\title{
Entrepreneurial Orientation, Creativity, and Productivity: The Influence of Self-leadership Strategies
}

\author{
John Denis Politis \\ Charles Darwin University, Sydney, Australia
}

\begin{abstract}
This study examines the influence of self-leadership strategies on the dimensions of entrepreneurial orientation, creativity, and productivity. It also investigates the psychometric properties of the relatively newly developed self-leadership measurement instrument. The study involves a questionnaire-based survey of employees from a perceived innovative organisation operating in the United Arab Emirates. A total of 255 employees participated in the study. The responses were subject to a serious of factor, correlation and regression analyses using SPSS and structural equation modeling. The findings indicate that the second order factor of self-leadership behavioural-focused strategies has a significant and strong effect on entrepreneurial orientation, which in turn enhances influences on creativity and productivity. Furthermore, the second order factor of self-leadership natural reward strategies has no effect on entrepreneurial orientation, suggesting that strategies that seek work activities which are pleasant and enjoyable neither affect the dimensions of entrepreneurial orientation, nor the dimensions of creativity and productivity. Results also showed that self-leadership behavioural-focused strategies accounted for $51 \%$ of the variance in entrepreneurial orientation, and $40 \%$ and $52 \%$ of the variance in creativity and productivity, respectively. The findings also showed that entrepreneurial orientation impacts significantly the dimensions of creativity and productivity. In conclusion, the findings clearly suggest that organisations should train and/or hire those employees who encompass strategies that are intended to strengthen positive, desirable behaviours, such as self-goal setting, self-observation, self-reward, self-punishment, and self-practice, if they wish to maintain and/or increase innovativeness, pro-activeness, creativity, and productivity. Directions for future research and practical implications for leadership and business approaches are discussed.
\end{abstract}

Keywords: behavioural-focused strategies, creativity, entrepreneurial orientation, natural reward strategies, productivity, self-leadership

\section{Introduction}

According to the literature, self-leadership addresses high-powered right brain activity and lays the foundation for effective self-influence and continuous improvement. Self-leadership involves the influence people exert over themselves to achieve the self-motivation and self-direction needed to accomplish desirable outcomes (Manz, 1992; Neck \& Manz, 1996). Three distinct categories of self-leadership influence succeeding outcomes: constructive thought pattern strategies (e.g., optimistic and obstacle thought patterns),

John Denis Politis, Ph.D., senior academic in management, School of Business, Charles Darwin University, Sydney, Australia.

Correspondence concerning this article should be addressed to John Denis Politis, Charles Darwin University, Level 10, 815 George Street, Haymarket, NSW 2000, Australia. E-mail: jdpolitis@gmail.com. 
behavioural-focused strategies, and natural reward strategies (Manz, 1986; 1992). Although the optimistic thought patterns strategies are found to support the relationship between creativity and productivity, and to a large extend entrepreneurship (Politis \& Breman, 2011), there is no relationship found between self-leadership natural reward strategies and entrepreneurial orientation in a study undertaken by J. D. Politis and D. J. Politis (2009). Thus, it is not known whether self-leadership natural reward strategies translate into entrepreneurial orientation, creativity, and productivity, because in J. D. Politis and D. J. Politis's study (2009), the strategies that seek work activities which are pleasant and enjoyable have no effect on the dimensions of entrepreneurial orientation. Therefore, there is a gap in the literature examining whether self-leadership behavioural-focused strategies have greater effect on entrepreneurial orientation, creativity, and productivity compared to the effect derived from self-leadership natural reward strategies.

This study intends to address: (i) the relationship among self-leadership behavioural-focused strategies, self-leadership natural reward strategies, and entrepreneurial orientation; (ii) the relationship between entrepreneurial orientation and creativity and productivity; (iii) whether entrepreneurial orientation mediates the self-leadership-creativity relationship; (iv) whether entrepreneurial orientation mediates the self-leadership-self-rating productivity relationship; and (v) the psychometric properties of the relatively newly developed self-leadership measurement instrument.

\section{Literature Review and Hypotheses}

The underlying notion of self-leadership strategies has its roots in Bandura's social learning theory (1977) and Bandura's social cognitive theory (1986), whereby employees influence their own cognition, motivation, and behaviour (Yun, Cox, \& Sims, 2006) in order to manage their activities. However, Manz (1986; 1992) developed a theory which expands Bandura's previous work by viewing employees as having internal self-control, self-regulation, self-motivation, self-direction, and self-evaluation needed to achieve desirable outcomes in their daily lives. According to Manz (1986; 1992), there are three distinct categories of self-leadership that influence anticipated outcomes, namely: constructive thought pattern strategies (e.g., optimistic and obstacle thought patterns); behavioural-focused strategies; and natural reward strategies. The primary focus of this paper is to investigate the relationship of the behavioural-focused strategies and natural reward strategies on the outcome constructs of entrepreneurial orientation, creativity, and productivity.

\section{Self-leadership Behavioural Focused Strategies}

According to the literature, the sub-strategies of self-observation, cueing strategies, self-goal setting, self-reward, self-punishment, and practice compose Manz's overall self-leadership behavioural focus strategies (1992). The definition of these strategies has been adopted from Manz (1992): (i) Self-observation describes the extent to which employees can (or try to) keep track of the progress of their work or are aware of their own work performance; (ii) cueing strategies represent the extent to which employees use physical cues to remind themselves of their important tasks; (iii) self-goal setting represents the extent to which employees provide self-direction using personal goals; (iv) self-reward represents the extent to which employees influence themselves using rewards at both a physical and mental level; (v) self-punishment represents the extent to which employees correct their undesirable behaviours through the feeling of guilt, when they fail to do something; and (vi) practice represents the extent to which employees improve themselves through the process of practicing an activity before performing it. 
It is argued in the literature that self-leadership to a large extent overlaps with self-management, because of their common theoretical background (Manz, 1992; Bandura, 1977; 1982). It is also found that self-leadership behavioural focused strategies improved job satisfaction (Politis, 2007), job satisfaction, and team performance (Politis, 2006). It is thus plausible that self-leadership behavioural focused strategies will be positively related to entrepreneurial orientation. This relationship is expressed in the following hypothesis:

Hypothesis 1: Self-leadership behavioural focused strategies will have a positive and direct effect on entrepreneurial orientation.

Moreover, the effect of self-leadership behavioural focused strategies on team performance was mediated by intrinsic and extrinsic satisfaction (Politis, 2006). Thus, entrepreneurial orientation may be a behaviour through which self-leadership behavioural focused strategies affect creativity and productivity. It is thus expected that entrepreneurial orientation will mediate the relationship between self-leadership behavioural focused strategies and creativity and productivity. These relationships are represented in the following hypotheses:

Hypothesis 2: Entrepreneurial orientation mediates the relationship between self-leadership behavioural focused strategies and creativity;

Hypothesis 3: Entrepreneurial orientation mediates the relationship between self-leadership behavioural focused strategies and productivity.

\section{Self-leadership Natural Reward Strategies}

Self-leadership natural reward strategies are mainly based on Deci's intrinsic motivation theory (1975) and in particular on cognitive evaluation theory (Deci \& Ryan, 1985), whereby natural reward strategies emphasise on intrinsically motivating activities. Manz (1992) has presented five natural reward strategies that could promote self-direction and self-motivation (DiLiello \& Houghton, 2006; Manz \& Neck, 2004), namely: distinguishing natural rewards, choosing pleasant surroundings, building natural rewarding activities at work, focusing on pleasant aspects of work, and focusing on natural rewards rather than external rewards. Details of these strategies can be found in study of Manz (1992).

Although there is limited empirical evidence examining the relationship between self-leadership natural reward strategies and entrepreneurial orientation and between creativity and productivity, one recent cross-cultural study (in the Netherlands and the United Arab Emirates) found positive relationships between constructive thought pattern strategies (e.g., optimistic thinking), and the dimensions of entrepreneurial orientation, and creativity and productivity (Politis \& Breman, 2011). As constructive thought pattern strategy is one of Manz's three distinct categories of self-leadership (1992) and shares a common theoretical background, it is reasonable to assume that the factors representing self-leadership natural reward strategies will be predictive factors of entrepreneurial orientation, creativity, and productivity. This relationship presents the following hypothesis:

Hypothesis 4: Self-leadership natural rewards strategies will have a positive and direct effect on entrepreneurial orientation.

Moreover, for the same reason discussed earlier, it is expected that entrepreneurial orientation will mediate the relationship between self-leadership natural reward strategies and creativity and productivity. These relationships are represented in the following hypotheses:

Hypothesis 5: Entrepreneurial orientation mediates the relationship between self-leadership natural reward strategies and creativity; 
Hypothesis 6: Entrepreneurial orientation mediates the relationship between self-leadership natural reward strategies and productivity.

Finally, there is a plethora of writings supporting the relationship among entrepreneurial orientation, creativity, and productivity (J. D. Politis \& N. J. Politis, 2012; Politis \& Breman, 2011; D’Intino, Goldsby, Houghton, \& Neck, 2007; Amabile, Conti, Coon, Lazenby, \& Herron, 1996). It is thus reasonable to assume that entrepreneurial orientation will be positively related with creativity and productivity. This assumption is expressed in the following hypotheses:

Hypothesis 7: Correlations of creativity with entrepreneurial orientation will be strong, positive, and significant;

Hypothesis 8: Correlations of productivity with entrepreneurial orientation will be strong, positive, and significant.

\section{Research Method}

\section{Research Subjects}

Employees from a perceived innovative medium sized service organisation operating in the United Arab Emirates (UAE) were examined in the study. This organisation is one of several UAE organisations which took part in a broader research study undertaken in October 2012. The study involves a questionnaire-based survey written in English measuring employees' entrepreneurial orientation, creativity, self-rated productivity, and the level of self-leadership strategies.

A total of 255 usable questionnaires were obtained from full time employees, who volunteered to participate in the study (68.7\% response rate). Their anonymity and confidentiality were guaranteed. Fifteen incomplete questionnaires were excluded from the final sample. The final sample consisted of $32.9 \%$ females and $67.1 \%$ males. The participants were relatively young as $82.7 \%$ were under the age of 30 , and only $2.8 \%$ being over the age of $46 ; 85.9 \%$ held their current position in the organisation for less than five years, and surprisingly enough $85.9 \%$ have known their immediate leaders for less than five years. It is implied in this result that the participating organisation is a new start-up operation (which is very typical in the UAE), as both employees and managers have commenced employment at the same time. In addition, $69.4 \%$ held the current position for five years, implying that there is a relatively low turnover, which was not common with UAE organisations prior to 2008. As for the participants level of education, only $2.0 \%$ did not graduate from high school and everybody else has received a higher diploma (46.7\%) or higher qualification in the English language.

\section{Analytical Procedure}

The IBM SPSS Statistics Version 20 was used to assess the measurement models through factor analyses (FAs). Moreover, the analysis of moment structures (AMOS) software (Arbuckle, 2007) was used for the structural model. A mixture of fit-indices was employed to assess the overall fit of the structural model. These included: the Chi-square to degrees of freedom $\left(x^{2} / \mathrm{df}\right)$; the goodness-of-fit (GFI); the adjusted goodness-of-fit (AGFI); the comparative fit index (CFI); the Tucker and Lewis index (TLI); the root mean square residual (RMR), and root mean square error approximation (RMSEA). As Jorskog and Sorbon (1993) suggested, the structural model fits the data well, when the values of GFI, AGFI, CFI, and TLI are greater than 0.90 ; and $x^{2} / \mathrm{df}$ is less than 3.0; RMR is less than 0.05; RMSEA is up to 0.08 ; and values greater than 0.10 are 
taken to be evidence of a poorly fitting model (Browne \& Cudeck, 1993). If the confirmatory factor analyses (CFAs) of the structural model indicate that the values of the fit-indices are equal to, or greater than, the recommended values (i.e., demonstrate adequate validity and reliability); it is then accepted as the best fitting model. Moreover, the measurement models were tested for convergent validity by computing the average variance extracted (AVE). Constructs with AVE $>0.5$ demonstrate adequate convergent validity (Fornell \& Larker, 1981).

\section{Research Results}

\section{Independent Variables}

Self-leadership behavioural-focused strategies were assessed using Manz's 18-item questionnaire (1992). The items measure self-observation, cueing strategies, self-goal setting, self-reward, self-punishment, and practice. Responses to the 18 items were made on a five-point Likert response scale with response options from "does not describe me at all" to "describes me very well". The results of the FAs supported the independence of the five factors: self-observation (three items, $\alpha=0.65$ ), self-goal setting (three items, $\alpha=0.72$ ), self-reward (two items, $\alpha=0.73$ ), self-punishment (three items, $\alpha=0.70$ ), and practice (three items, $\alpha=0.78$ ). The latent variable of cueing strategies was not supported and its Cronbach alpha was $\alpha=0.50$. In addition, one item from self-reward was not included for further analysis, due to cross loading. In addition, the measures achieve adequate convergent validity, as the average variance extracted (AVE) for each construct ranged from 0.45 to 0.69 (Fornell \& Larker, 1981).

Natural reward strategies were assessed using Manz's 15-item questionnaire (1992). The items measure the followings: distinguishing natural rewards, choosing pleasant surroundings, building natural rewarding activities at work, focusing on pleasant aspects of work, and focusing on natural rewards rather than external rewards. Responses to the 15 items were made on a five-point Likert response scale with response options from "does not describe me at all" to "describes me very well". The results of the FAs supported the independence of the five factors: distinguishing natural rewards (three items, $\alpha=0.66$ ), choosing pleasant surroundings (three items, $\alpha=0.75$ ), build natural rewarding activities at work (three items, $\alpha=0.70$ ), focus on pleasant aspects of work (three items, $\alpha=0.66$ ), and focus on natural rewards rather than external rewards (three items, $\alpha=0.73)$. The Cronbach alpha for two of the five latent variables $(\alpha=0.66)$ was marginally accepted. The AVE ranged from 0.40 to 0.56 suggesting that the natural reward strategies have sufficient convergent validity.

\section{Dependent Variables}

Entrepreneurial orientation constructs were assessed using Miller's scale (1983) which was further extended in the specialised literature (Covin \& Slevin, 1989); the scale consists of nine items measuring innovativeness, risk taking, proactiveness, and competitive aggressiveness. Entrepreneurial orientation was assessed on a five-point Likert response scale ( $1=$ very disagree; $5=$ very agree). The FAs results supported the factor of innovativeness (three items, $\alpha=0.74$ ), and the combined factor of pro-activeness, competitive aggressiveness and risk taking (six items, $\alpha=0.65$ ). The measures achieve adequate convergent validity as the AVE ranged from 0.45 to 0.63 .

Creativity and productivity were assessed using Amabile et al.'s 12-item KEYS instrument (1996). The instrument employs a four-point response scale $(1=$ never; 4 = always $)$. The FAs supported fully the factor of 
creativity (six items, $\alpha=0.84$ ) and productivity (six items, $\alpha=0.82$ ). The AVE for creativity and productivity were $\mathrm{AVE}=0.45$ and $\mathrm{AVE}=0.63$, respectively, suggesting adequate convergent validity.

The model in Figure 1 shows the hypothesised relationship among entrepreneurial orientation, creativity, productivity, self-leadership behavioural-focused strategies, and self-leadership natural reward strategies.

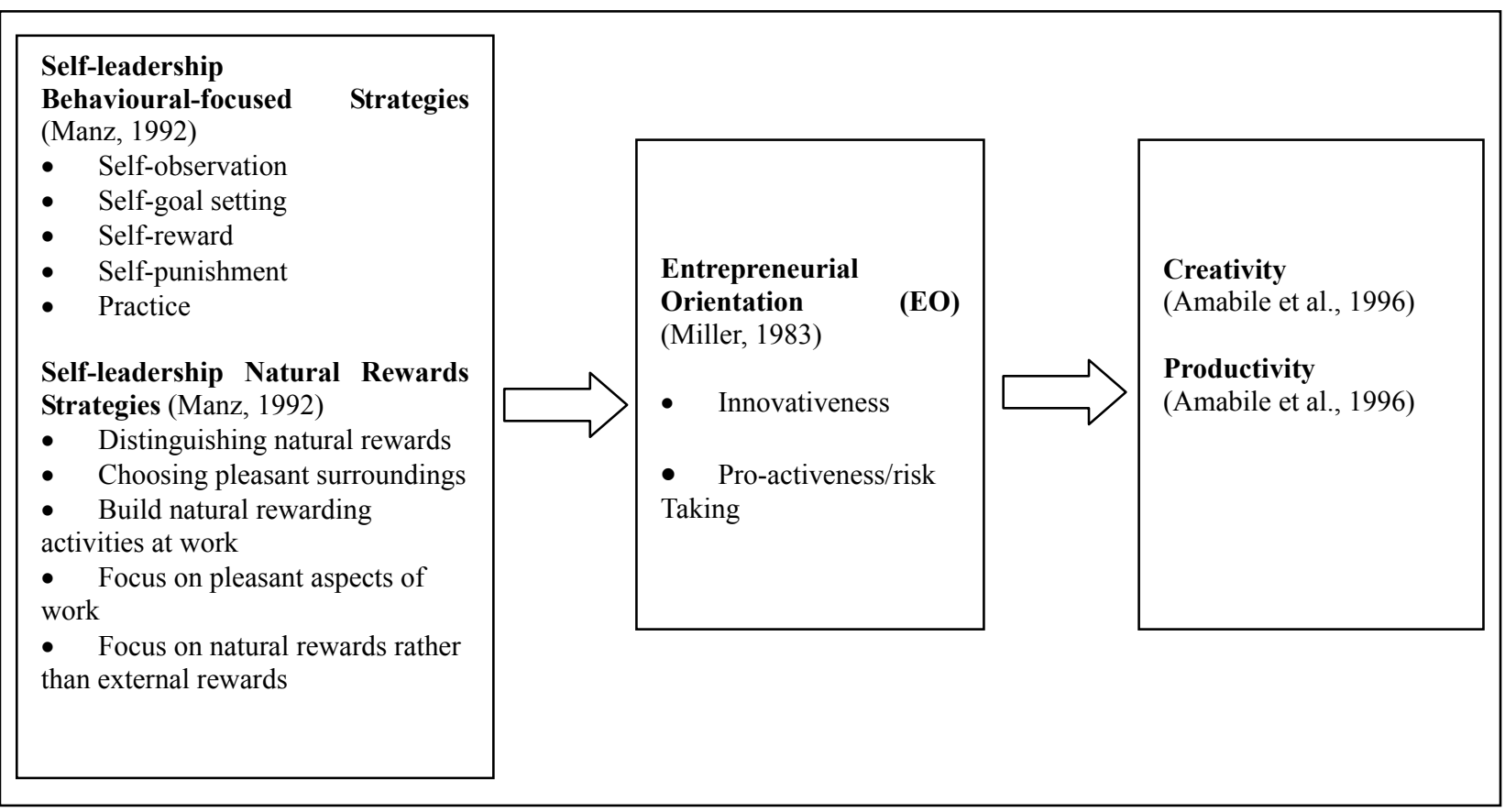

Figure 1. Summary of variables used in the paper.

\section{Analysis and Hypotheses Testing}

Descriptive analyses of responses for entrepreneurial orientation, creativity, productivity, and the self-leadership strategies were performed first to identify any prevailing patterns. Moreover, the hypothesised relationships among entrepreneurial orientation, creativity, productivity, and self-leadership measures were tested using Pearson's correlation coefficients. Table 1 contains the means, standard deviations, and the Pearson's correlations coefficient estimates for the first order factors investigated in this study.

Table 1

Means, Standard Deviations and Correlations Coefficient Estimates for Entrepreneurial Orientation, Creativity, Productivity, Self-leadership Behavioural-Focused Strategies, and Self-leadership Natural Reward Strategies

\begin{tabular}{|c|c|c|c|c|c|c|c|c|c|c|c|c|c|c|c|c|}
\hline Latent variable & Mean & $\sigma$ & 1 & 2 & 3 & 4 & 5 & 6 & 7 & 8 & 9 & 10 & 11 & 12 & 13 & 14 \\
\hline \multicolumn{17}{|c|}{ Self-leadership behavioural focused strategies-1st order factors } \\
\hline 1. Self-observation & 3.84 & 0.63 & 0.65 & & & & & & & & & & & & & \\
\hline 2. Self-goal Setting & 3.97 & 0.72 & 0.44 & 0.72 & & & & & & & & & & & & \\
\hline 3. Self-reward & 3.43 & 1.02 & 0.26 & 0.37 & 0.73 & & & & & & & & & & & \\
\hline 4. Self-punishment & 3.56 & 0.77 & 0.23 & 0.27 & 0.24 & 0.70 & & & & & & & & & & \\
\hline 5. Practice & 3.42 & 0.89 & 0.34 & 0.30 & 0.16 & 0.42 & 0.78 & & & & & & & & & \\
\hline
\end{tabular}

Self-leadership natural reward strategies-1st order factors

\begin{tabular}{llllllllll}
\hline $\begin{array}{l}\text { 6. Distinguishing natural } \\
\text { rewards }\end{array}$ & 3.86 & 0.67 & 0.46 & 0.43 & 0.27 & 0.34 & 0.38 & 0.66 & \\
$\begin{array}{l}\text { 7. Choosing pleasant } \\
\text { surroundings }\end{array}$ & 3.85 & 0.77 & 0.36 & 0.35 & 0.26 & 0.43 & 0.35 & 0.52 & 0.75
\end{tabular}


Table 1 continued

\begin{tabular}{|c|c|c|c|c|c|c|c|c|c|c|c|c|c|c|c|c|}
\hline Latent variable & Mean & $\sigma$ & 1 & 2 & 3 & 4 & 5 & 6 & 7 & 8 & 9 & 10 & 11 & 12 & 13 & 14 \\
\hline \multicolumn{17}{|c|}{ Self-leadership natural reward strategies-1 st order factors } \\
\hline $\begin{array}{l}\text { 8. Build natural rewarding } \\
\text { activities at work }\end{array}$ & 3.89 & 0.68 & 0.44 & 0.52 & 0.48 & 0.40 & 0.30 & 0.59 & 0.62 & 0.70 & & & & & & \\
\hline $\begin{array}{l}\text { 9. Focus on pleasant aspects } \\
\text { of work }\end{array}$ & 3.69 & 0.66 & 0.36 & 0.39 & 0.25 & 0.29 & 0.34 & 0.45 & 0.49 & 0.52 & 0.66 & & & & & \\
\hline $\begin{array}{l}\text { 10. Focus on natural rewards } \\
\text { rather than external rewards }\end{array}$ & 3.71 & 0.76 & 0.37 & 0.49 & 0.26 & 0.24 & 0.34 & 0.44 & 0.33 & 0.47 & 0.53 & .073 & & & & \\
\hline \multicolumn{17}{|c|}{ Outcome variables - 1 st order factors } \\
\hline 11. Innovativeness & 3.75 & 0.79 & 0.21 & 0.29 & - & 0.19 & 0.30 & 0.27 & 0.26 & 0.18 & 0.22 & 0.32 & 0.74 & & & \\
\hline 12. Proactiveness/risk taking & 3.56 & 0.61 & 0.26 & 0.39 & 0.40 & 0.26 & 0.18 & 0.23 & 0.16 & 0.32 & 0.43 & 0.48 & 0.36 & 0.65 & & \\
\hline 13. Creativity & 3.00 & 0.60 & 0.31 & 0.32 & 0.23 & - & - & 0.21 & - & 0.22 & 0.16 & 0.34 & 0.26 & 0.35 & 0.84 & \\
\hline 14. Productivity & 3.21 & 0.53 & 0.35 & 0.37 & 0.32 & 0.15 & - & 0.20 & - & 0.30 & 0.20 & 0.41 & 0.26 & 0.46 & 0.48 & 0.82 \\
\hline
\end{tabular}

Notes. $N=255$; Cronbach alpha reliability estimates $\left(\alpha_{\mathrm{s}}\right)$ are located on the diagonal; first order factors Person's correlation estimates, $r_{\mathrm{s}} \geq 0.16$ are statistically significant @ $p<0.01$ ( $r_{\mathrm{s}}$ if not reported, was not statistically significant).

Also the structural model of Figure 2 was examined using second order factors. The analysis revealed that the model of Figure 2 fits the data very well, with $\left(x^{2} / \mathrm{df}=2.68\right) ; \rho=0.01$; GFI $=0.97$; AGFI $=0.93$; CFI $=$ 0.97 ; TLI $=0.95 ;$ RMR $=0.013$; and RMSEA $=0.08$. Adding alternative paths (e.g., from self-leadership natural reward strategies to entrepreneurial orientation) led to a worse model fit, hence the model in Figure 2 was accepted as the best fitting model. As shown, there is no relationship between self-leadership natural rewards and entrepreneurial orientation. Standardised path estimates are provided to facilitate comparison of regression coefficients.

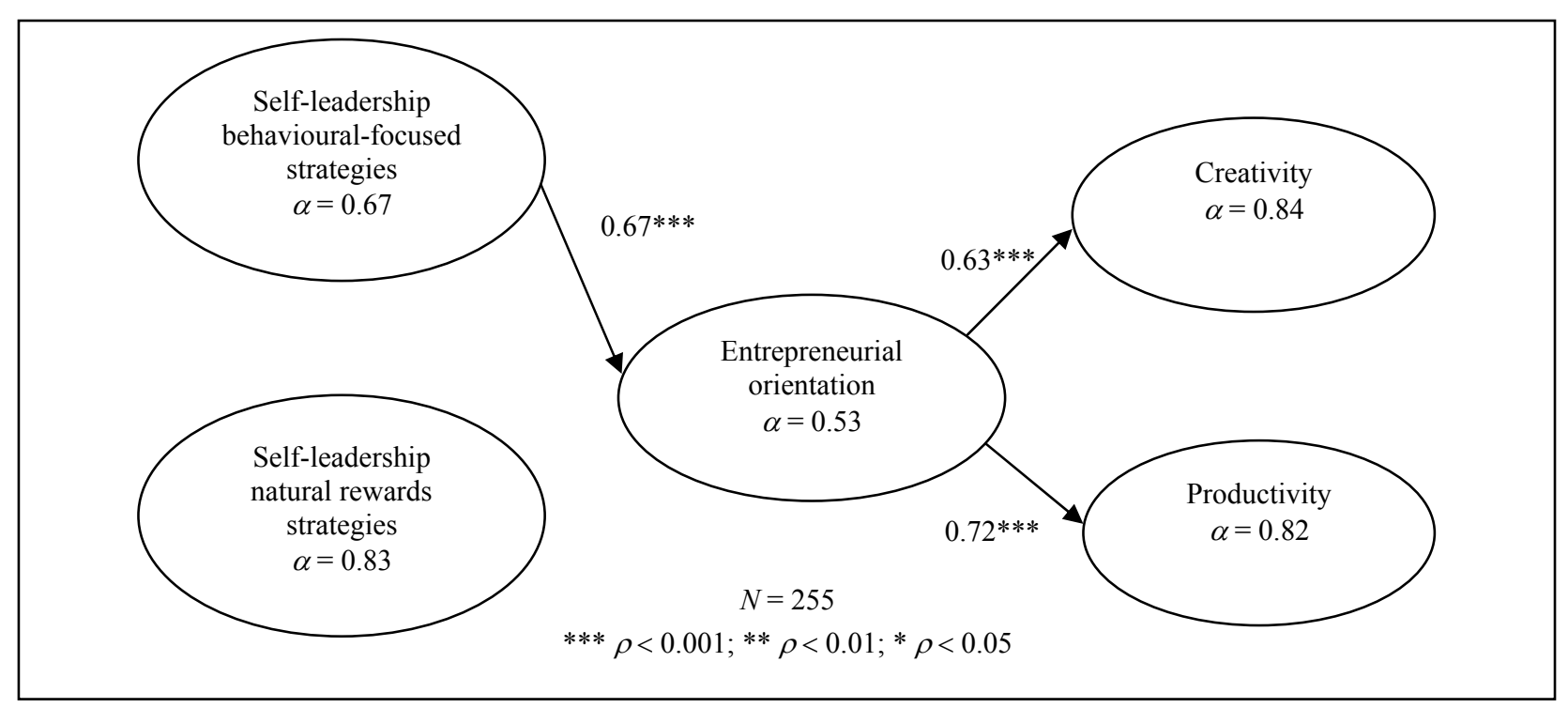

Figure 2. Second order factors structural model.

There are several important observations regarding Table 1. First, it can be noted that all first order factors display reliabilities greater than 0.65 which are close to the recommended value of 0.70 (Hair, Ringle, \& Sarstedt, 2011). Second, the AVE for each construct is greater than 0.4, suggesting adequate convergent validity for the constructs under consideration (Fornell \& Larker, 1981). In relation to the first order factors, the correlations among self-leadership behavioural focused strategies and self-leadership natural rewards strategies, 
and entrepreneurial orientation, creativity, and productivity are positive and significant. In other words, self-leadership strategies have a significant and positive effect on employees' entrepreneurial orientation, creativity, and productivity. The results of Table 1 however could not explain, if entrepreneurial orientation acts as a mediating variable between self-leadership strategies and creativity and productivity. The findings of the path model of Figure 2 clearly showed that self-leadership behavioural focused strategies strongly influence entrepreneurial orientation, which in turn has a strong impact on both creativity and productivity. Theoretical and empirical rationale for the hypothesised relations between constructs is discussed in the following section.

\section{The Effects of Modelling Variables}

The findings derived from the first order factors supported the eight hypotheses. As predicted, H1 was supported by the data of this study, in that the underlying dimensions of self-leadership behavioural focused strategies were positively and significantly related to underlying dimensions of entrepreneurial orientation. That is innovativeness related with self-observation, self-goal setting, self-punishment, and practice $(r=0.21, \rho<$ $0.01 ; r=0.29, \rho<0.01 ; r=0.19, \rho<0.01$; and $r=0.30, \rho<0.01$, respectively). Moreover, pro-activeness/risk was related with self-observation, self-goal setting, self-reward, self-punishment, and practice $(r=0.26, \rho<$ $0.01 ; r=0.39, \rho<0.01 ; r=0.40, \rho<0.01 ; r=0.26, \rho<0.01$; and $r=0.18, \rho<0.01$, respectively).

Moreover, the underlying dimensions of self-leadership natural reward strategies were positively and significantly related to underlying dimensions of entrepreneurial orientation, hence fully supporting H4. Specifically, innovativeness was related with distinguishing natural rewards, choosing pleasant surroundings, building natural rewarding activities at work, focusing on pleasant aspects of work, and focusing on natural rewards rather than external rewards $(r=0.27, \rho<0.01 ; \mathrm{r}=0.26, \rho<0.01 ; r=0.18, \rho<0.01 ; r=0.22, \rho<$ 0.01 ; and $r=0.32, \rho<0.01$, respectively). Moreover, pro-activeness/risk was related with distinguishing natural rewards, choosing pleasant surroundings, building natural rewarding activities at work, focusing on pleasant aspects of work, and focusing on natural rewards rather than external rewards $(r=0.23, \rho<0.01 ; r=$ $0.16, \rho<0.01 ; r=0.32, \rho<0.01 ; r=0.43, \rho<0.01$; and $r=0.48, \rho<0.01$, respectively).

However, the results of the structural model supported only H1. Specifically, the second order factor of self-leadership behavioural focused strategies has a strong, positive, and significant relationship with entrepreneurial orientation $(r=0.67, \rho<0.001)$, which in turn influenced creativity and productivity. As a result, entrepreneurial orientation mediates the relationship between self-leadership behavioural focused strategies and creativity and productivity, hence, supporting $\mathrm{H} 2$ and $\mathrm{H} 3$.

The results however did not confirm the direct relationship between the second order factor of self-leadership natural rewards strategies and entrepreneurial orientation, hence H4 was not supported. As a result, entrepreneurial orientation did not mediate the relationship between self-leadership natural reward strategies and creativity, hence H5 was not supported by the findings of the structural model. Moreover, entrepreneurial orientation did not mediate the relationship between self-leadership natural reward strategies and productivity, hence H6 was not supported by the structural model.

The results also showed strong, positive, and significant relationship between creativity and innovativeness and pro-activeness/risk taking $(r=0.26, \rho<0.01 ; r=0.35, \rho<0.01$, respectively). Furthermore, the relationship between entrepreneurial orientation (2nd order factor) and creativity was significant, strong, and positive ( $r=0.63, \rho<0.001)$, hence $\mathrm{H} 7$ was supported by the 1 st and 2 nd order factors. 
Finally, the relationship among productivity and innovativeness and pro-activeness/risk taking was strong, positive, and significant $(r=0.26, \rho<0.01 ; r=0.46, \rho<0.01$, respectively). Moreover, the relationship between entrepreneurial orientation (2nd order factor) and productivity was significant, strong, and positive ( $r=$ $0.72, \rho<0.001)$, hence, supporting $\mathrm{H} 8$.

\section{Discussion}

The purpose of this study was to examine: (i) the relationship among self-leadership behavioural-focused strategies, self-leadership natural reward strategies, and entrepreneurial orientation; (ii) the relationship among entrepreneurial orientation, creativity, and productivity; (iii) whether entrepreneurial orientation mediates the self-leadership-creativity relationship; and (iv) whether the entrepreneurial orientation mediates the self-leadership-self-rating productivity relationship. Finally, the study examined the psychometric properties of Manz's self-leadership measurement instrument (1992).

The findings of this study clearly support that self-leadership behavioural focused strategy is a significant predictor of entrepreneurial orientation, as its association (at the higher order factor level) with entrepreneurial orientation is positive, strong, and significant $(r=0.67, \rho<0.001)$, which in turn influenced creativity and productivity. The study also showed that the relationship among self-leadership behavioural focused strategies, creative, and productivity is mediated through the underlying constructs of entrepreneurial orientation.

As discussed earlier, the direct relationship between the 2nd order factor of self-leadership natural rewards strategies and entrepreneurial orientation was not confirmed by the data of this study. Moreover, the underlying constructs of self-leadership natural rewards strategies (1st order factors) have a positive effect on the underlying constructs of entrepreneurial orientation (see Table 1). In addition, controlling for self-leadership behavioural focused strategies, the structural model findings show a positive and significant relationship between self-leadership natural rewards strategies and entrepreneurial orientation $(r=0.62, \rho<0.001)$. It should be noted that controlling for self-leadership behavioural focused strategies led to a worse model fit compared to the model shown in Figure 2. These results raise questions over the possible harmful effects on entrepreneurial orientation, if both self-leadership strategies (self-leadership behavioural focused strategies and self-leadership natural reward strategies) act simultaneously on the underlying dimensions of entrepreneurial orientation. That is because high levels of internal self-control (self-leadership behavioural focused strategies) may cause an increase in anxiety in organisations that facilitate innovation and creativity, hence the intrinsically motivating activities (self-leadership natural rewards strategies) cannot be operative or impaired in such conditions.

It is suggested in these findings that entrepreneurial orientation by extension creativity and productivity could be enhanced, if self-leadership natural rewards strategies act alone. However, such proclamation cannot be fully justified, because in a previous study, strategies seek work activities which are pleasant and enjoyable (e.g., self-leadership natural reward strategies) and have no effect on the dimensions of entrepreneurial orientation (J. D. Politis \& D. J. Politis, 2009). In that regard, it would be interesting to examine the combined effect of self-leadership behavioural focused strategies and self-leadership natural reward strategies on the "stimulant" determinants (Amabile et al., 1996) of the creative work environment providing another condition that may facilitate employees' entrepreneurial orientation.

The findings of this study clearly support that entrepreneurial orientation is a significant predictor of creativity and productivity, as its association (at the 1st and 2nd order factor level) with creativity and 
productivity is positive, strong, and significant. These findings suggest that employees who are commonly known as entrepreneurial oriented (innovative, proactive and risks takers) are open-minded to new information and proactively and extensively engage in environmental scanning (Miles \& Snow, 1978) in order to find new ways of doing things productively (Wang, 2008); they seize an opportunity in order to shape the environment aiming at increasing productivity.

\section{Limitations and Future Research Directions}

There are a number of limitations that need to be addressed, when considering the findings. The first limitation is related to the self-leadership behavioural focused strategies questionnaire, which needs to be reviewed and refined, as the latent variable of cueing strategies was not supported, because its Cronbach alpha was $\alpha=0.50$. Second, further research would be needed to examine the combined effect of self-leadership behavioural focused strategies and self-leadership natural reward strategies on "stimulant" determinants (Amabile et al., 1996) of the creative work environment, providing an additional condition that may facilitate employees' entrepreneurial orientation. Third, the cross-sectional design of the study renders it vulnerable to problems associated with common method variance. To account for the problem of common method variance, future research would be needed to collect data from multiple sources (Spector, 1987) and perform longitudinal studies to explore in greater detail the entrepreneurial orientation—self-leadership relationships.

\section{Conclusions}

In conclusion, the findings highlight the need for organisations to consider employing and/or develop employees that possess self-leadership behavioural focused strategies, which in turn enhance their entrepreneurial orientation and consequently result in increased creativity and productivity. Thus, these organisations could maintain their competitive advantage through new products and services and new business productive models. Moreover, the psychometric properties of the relatively newly developed self-leadership measurement instrument were supported for most of the 1st order factors.

This study contributes to an emerging research of self-leadership strategies and entrepreneurial orientation, which thus far has not fully explored the combined effect of self-leadership behavioural focused strategies and self-leadership natural rewards strategies on the dimensions of entrepreneurial orientation, creativity, and productivity. The highlight of the paper is that the two self-leadership strategies (self-leadership behavioural focused strategies and self-leadership natural reward strategies) should not act simultaneously on the dimensions of entrepreneurial orientation.

\section{References}

Amabile, T. M., Conti, R., Coon, H., Lazenby, J., \& Herron, M. (1996). Assessing the work environment for creativity. Academy of Management Journal, 39, 1154-1184.

Arbuckle, J. L. (2007). Analysis of moment structures (AMOS), user's guide (16th ed.). Spring House: AMOS Development Corporation.

Bandura, A. (1977). A social learning theory. Englewood Cliffs, New Jersey: Prentice-Hall.

Bandura, A. (1982). Self-efficacy mechanism in human agency. American Psychologist, 37, 122-147.

Bandura, A. (1986). Social foundations of thought and action: A social cognitive theory. Englewood Cliffs, New Jersey: Prentice-Hall.

Browne, M. W., \& Cudeck. R. (1993). Alternative ways of assessing model fit. In K. A. Bollen and J. L. Scott (Eds.), Testing structural equations models (pp. 36-62). Newbury Park, California: Sage.

Covin, J. G., \& Slevin, D. P. (1989). Strategic management of small firms in hostile and benign environment. Strategic Management Journal, 10, 75-87. 
D'Intino, R. S., Goldsby, M. G., Houghton, J. D., \& Neck, C. P. (2007). Self-leadership: A process for entrepreneurial success. Journal of Leadership and Organizational Studies, 13, 105-120.

Deci, E. L. (1975). Intrinsic motivation. New York: Plenum.

Deci, E. L., \& Ryan, R. M. (1985). Intrinsic motivation and self-determination in human behaviour. New York: Plenum.

DiLiello, T. C., \& Houghton, J. D. (2006). Maximizing organizational leadership capacity for the future: Toward a model of self-leadership, innovation and creativity. Journal of Managerial Psychology, 21(4), 319-337.

Fornell, C., \& Larker, D. F. (1981). Evaluating structural equation models with unobservable variables and measurement error. Journal of Marketing Research, 18, 39-50.

Hair, J. F., Ringle, C. M., \& Sarstedt, M. (2011). PLS-SEM: Indeed a silver bullet. The Journal of Marketing Theory and Practice, 19(2), 139-152.

Jorskog, K. G., \& Sorbon, D. (1993). LISREL 8: Structural equation modelling with the SIMPLIS command language. Chicago, IL: Scientific International Software.

Manz, C. C. (1986). Self-leadership: Toward an expanded theory of self-influence processes in organizations. Academy of Management Review, 11(3), 585-600.

Manz, C. C. (1992). Mastering self-leadership: Empowering yourself for personal excellence. Englewood Cliffs, New Jersey: Prentice-Hall.

Manz, C. C., \& Neck, C. P. (2004). Mastering self-leadership: Empowering yourself for personal excellence (2nd ed.). Upper Saddle River, New Jersey: Prentice Hall.

Miles, R. E., \& Snow, C. C. (1978). Organizational strategy, structure and process. New York: McGraw-Hill.

Miller, D. (1983). The correlates of entrepreneurship in three types of firms. Management Science, 29(7), 770-791.

Neck, C., \& Manz, C. C. (1996). Thought self-leadership: The impact of mental strategies training on employee cognition, behaviour, and affect. Journal of Organizational Behaviour, 17, 445-467.

Politis J. D., \& Politis, N. J. (2012). The art of virtual leadership, entrepreneurial orientation, creativity and productivity. Proceedings from ICSB '12: The 57th International Council for Small Business World Conference, Wellington, New Zealand.

Politis, J. D. (2006). Self-leadership behavioural-focused strategies and team performance: The mediating influence of job Satisfaction. The Leadership and Organizational Development Journal, 27(3), 203-216.

Politis, J. D. (2007). The relationship between self-leadership behavioural-focused strategies, job satisfaction and quality function deployment. Proceedings from ECMLG '07: The Third European Conference on Management, Leadership and Governance, University of Winchester, United Kingdom.

Politis, J. D., \& Breman, P. (2011). Self-leadership, entrepreneurship, creativity and productivity in the Netherlands and the United Arab Emirates. Proceedings from ICSB '11: The 56th International Council for Small Business World Conference, Stockholm, Sweden.

Politis, J. D., \& Politis, D. J. (2009). The relationship of mainstream leadership styles to entrepreneurial orientation. Proceedings from ECMLG '09: The Fifth European Conference on Management, Leadership and Governance, Hellenic American University and ATExcelixi, Athens, Greece.

Spector, P. E. (1987). Method variance as an artifact in self-reported affect and perceptions at work: Myth or significant problem. Journal of Applied Psychology, 72, 438-443.

Wang, C. L. (2008). Entrepreneurial orientation, learning orientation and firm performance. Entrepreneurship Theory and Practice, 32(4), 635-656.

Yun, S., Cox, J., \& Sims, H. P. (2006). The forgotten follower: A contingency model of leadership and follower self-leadership. Journal of Managerial Psychology, 21(4), 374-388. 